\title{
DETERMINATION OF HOMOCYSTEINE IN URINE AND SALIVA BY MI- CROCHIP ELECTROPHORESIS
}

\author{
PETER TrošKa *1, ANNA MANDŽÁKOVÁ ${ }^{1}$, JASNA HRAdSKI ${ }^{1}$, JURAJ ŠEVČíK ${ }^{2}$, AND MARIÁN \\ MASÁR ${ }^{1}$ \\ ${ }^{1}$ Department of Analytical Chemistry, Faculty of Natural Sciences, Comenius University in Bratislava, \\ Mlynská dolina $\mathrm{CH}-2$, Ilkovičova 6, SK-84215 Bratislava, SLOVAK REPUBLIC \\ ${ }^{2}$ Department of Analytical Chemistry, Faculty of Science, Palacký University Olomouc, 17. listopadu 12, \\ CZ-77146 Olomouc, CZECH REPUBLIC
}

\begin{abstract}
An online combination of isotachophoresis (ITP) and capillary zone electrophoresis (CZE) was employed on a microchip with a column-coupling technology for the determination of homocysteine in various body fluids. ITP with its high concentration ability was used as a sample pretreatment and injection technique for CZE, which facilitated the rapid and sensitive determination of homocysteine. The resolution of the analyte from other constituents present in real complex samples was enhanced by discrete spacers, which were added to the injected sample. A solid-phase microextraction (SPME) pretreatment technique based on silver- and barium-form resins was used prior to the ITP-CZE analysis to remove high concentrations of chloride and sulfate naturally present in the analyzed samples. The combination of the micropretreatment and microelectrophoresis techniques facilitated the determination of trace concentrations of homocysteine in samples of urine and saliva.
\end{abstract}

Keywords: homocysteine, body fluids, microchip electrophoresis, solid-phase microextraction

\section{Introduction}

Homocysteine (Hcy) is a non-proteinogenic sulfurcontaining amino acid whose metabolism is at the intersection of two metabolic pathways: remethylation and transsulfuration. In remethylation, Hcy acquires a methyl group from N5-methyltetrahydrofolate or from betaine to form methionine. The reaction with N5methyltetrahydrofolate occurs in all tissues and is vitamin B12-dependent, whereas the reaction with betaine is confined mainly to the liver and is vitamin B12-independent. A considerable proportion of methionine is then activated by ATP to form S-adenosylmethionine [1].

Increased concentration levels of Hcy in body fluids are considered to be an important risk factor or marker of various diseases, particularly cardiovascular ones [2]. In review papers [3-5], individual methods of determining Hcy in biological samples are summarized. Analytical methods using high-performance liquid chromatography (HPLC) to separate Hcy are some of the most commonly used. HPLC methods for the quantification of Hcy utilize derivatization procedures as well as procedures with non-derivatized Hcy by electrochemical detection (ECD). The growing interest in clinical analyses has generated increased attention due to the rapid determination of Hcy using automated methods. For this reason, the immunoas-

\footnotetext{
*Correspondence: peter.troska@uniba.sk
}

say of Hcy in plasma has become a preferred analytical approach [5].

Recently several procedures have been published for the determination of Hcy by capillary electrophoresis (CE). CE compared to HPLC is more advantageous in terms of the need for a very small sample volume, good resolution, short analysis time, simplicity of automation and elimination of various (toxic) solvents. This is evidenced by many of the works that have dealt with the determination of Hcy in body fluids, e.g. in plasma [6-18], serum [13] or urine [16, 19]. Most of them dealt with the use of laser-induced fluorescence (LIF) as a detection technique, however, UV detection was also used.

A miniaturized form of $\mathrm{CE}$, microchip electrophoresis (MCE), was used for the separation and detection of Hcy and glutathione. The analysis time on the glass microchip using amperometric detection was less than 80 s [6]. A polydimethylsiloxane (PDMS) microchip produced by a simple photolithographic technique facilitated the rapid separation of HCy and cysteine [20]. MCE analyses are more favorable than CE because they are considerably shorter, achieve higher degrees of separation efficiency and, in particular, reduce overall costs associated with chemical consumption and waste production.

This paper deals with the development of a new method for the determination of Hcy in various body fluids on a microchip with coupled-channels (CC). The 


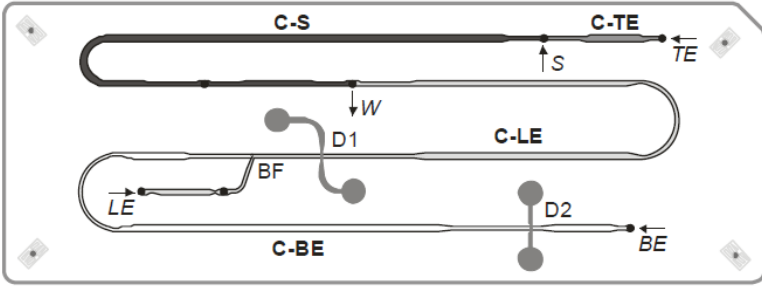

Figure 1: A scheme of the CC microchip with conductivity detection. C-LE = the first (ITP) separation channel (volume of $4.5 \mu \mathrm{L}$ ) filled with a leading electrolyte; $\mathrm{C}-\mathrm{BE}=$ the second (CZE) separation channel (volume of $4.3 \mu \mathrm{L}$ ) filled with a background electrolyte; $\mathrm{C}-\mathrm{TE}=$ the third channel (volume of $0.8 \mu \mathrm{L}$ ) filled with a terminating electrolyte; $\mathrm{C}-\mathrm{S}=$ sample injection channel (volume of $9.9 \mu \mathrm{L})$; D1, D2 = Pt conductivity sensors; $\mathrm{BF}=$ bifurcation section; BE, LE, TE, $\mathrm{S}=$ inlets for the background, leading, terminating and sample solutions to the microchip channels, respectively; $\mathrm{W}=$ an outlet channel for the waste container.

CC technology employed on the microchip with contact conductivity detection enables online capillary zone electrophoresis (CZE) to be coupled with the isotachophoresis (ITP) sample pretreatment. Samples of urine and saliva were simplified by solid-phase microextraction (SPME) prior to the ITP-CZE separations on the microchip. SPME based on silver- and barium-form resins provided a high degree of compatibility with MCE and a high level of selectivity, whilst simultaneously removing a huge amount of chloride and sulfate in the analyzed samples of body fluids.

\section{Experimental}

ITP-CZE separations were carried out on a poly(methyl methacrylate) microchip (Fig.1) with the CC technique and integrated conductivity detection sensors (IonChip $^{\mathrm{TM}}$ 3.0, Merck, Darmstadt, Germany).

Chemicals used for the preparation of electrolyte solutions and model samples were obtained from Sigma-Aldrich (Bratislava, Slovakia), Fluka ChemikaBiochemika (Buchs, Switzerland), Serva Electrophoresis $\mathrm{GmbH}$ (Heidelberg, Germany) and Erba Lachema s.r.o. (Brno, Czech Republic). Samples of urine and saliva were collected from volunteers. Before the analysis, the samples were homogenized and analyzed after being diluted appropriately with deionized water, and pretreated by SPME to remove chloride and sulfate. Solid-phase extraction (SPE) microcolumns of $0.5 \mathrm{~mL}$ in volume containing silver- and barium-form resins (Alltech, Grace Davison Discovery Sciences, Deerfield, Illinois, USA) were used for this purpose.

\section{Results and Discussion}

ITP-CZE separations were performed in a hydrodynamically closed separation system with suppressed electroos-

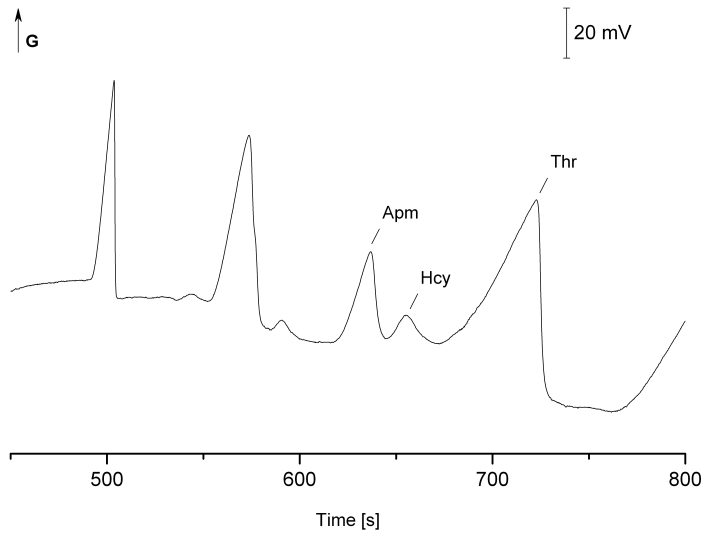

Figure 2: Electropherogram from the ITP-CZE separation of Hcy in the presence of discrete spacers. The sample injected onto the microchip: $100 \mu \mathrm{mol} / \mathrm{L} \mathrm{Apm}, 15 \mu \mathrm{mol} / \mathrm{L}$ Hcy, $150 \mu \mathrm{mol} / \mathrm{L}$ Thr in a $50 \%$ terminating electrolyte. Apm $=$ aminopimelate Hcy $=$ homocysteine $; \mathrm{Thr}=$ threonine; $\mathrm{G}=$ conductivity.

motic flow. These working conditions effectively reduce the fluctuations in the total migration velocity of the analytes which is crucial to obtain reproducible results, especially on the microchip with short separation paths [21]. In the ITP separations, a leading electrolyte with a $\mathrm{pH}$ of 9.1 and glycine as a terminating electrolyte were used. In the CZE step of the ITP-CZE technique, the $\mathrm{pH}$ of the background electrolyte was 9.8 .

The ITP realized in the first separation channel on the microchip (Fig. 1) preconcentrates the analyte and other constituents of the sample for the CZE separation step. On the other hand, the close migration configuration of the constituents in the ITP stage of the ITP-CZE technique can be a limiting factor for achieving the required resolution of the analyte from matrix constituents, especially on the microchip with short separation channels. In such a case, discrete spacers (DSs) are effectively used to define the fraction of the sample transferred to the second CZE channel when the CC technique is employed. Then, the constituents of the sample migrating outside of the mobility interval defined by the DSs are removed from the separation system. In this way, ITP works as an online sample clean-up technique prior to the CZE. In our case aminopimelate and threonine were used as the front and rear DSs, and the undesirable constituents of the sample were electrophoretically removed from the separation system by column switching prior to the CZE separation realized in the second channel (Fig. 2).

A $1.4 \mu \mathrm{mol} / \mathrm{L}$ limit of detection (LOD) for Hcy was obtained by the ITP-CZE technique on the microchip. A relatively large volume of the sample that was injected onto the microchip $(9.9 \mu \mathrm{l})$ contributed to achieving the low value of LOD when a universal and relatively low-sensitive conductivity detector was used. Under the working and separation conditions employed, the reproducible migration velocities (the relative standard devi- 


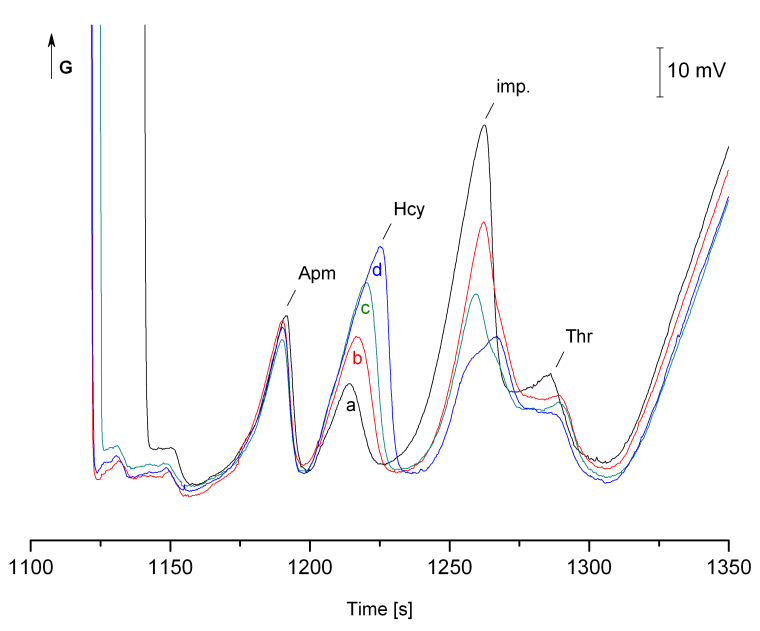

Figure 3: Electropherograms from ITP-CZE analyses of urine samples after SPME pretreatment with various additions of Hcy. Sample injected on the microchip: urine diluted twice, $400 \mu \mathrm{mol} / \mathrm{L} \mathrm{Apm,} 200 \mu \mathrm{mol} / \mathrm{L}$ Thr in 50 $\%$ terminating electrolyte with (a) 0; (b) 10; (c) 20; (d) 40 $\mu \mathrm{mol} / \mathrm{L} \mathrm{Hcy} . \mathrm{Apm}=$ aminopimelate; Hcy = homocysteine; $\mathrm{Thr}=$ threonine; imp. $=$ impurity; $\mathrm{G}=$ conductivity.

ations (RSDs) of migration times were between 0.5 and $1.2 \%$ ) and determinations of trace concentrations of Hcy (RSDs of peak areas were $1.2 \%$ ) were achieved.

Considering the high concentration levels of chloride and sulfate in urine and saliva samples, these interfering anions were removed before ITP-CZE analysis from real samples. For this purpose, SPME using silver- and barium-form resins was conducted. The content of Hcy in samples of body fluid was evaluated by the method of standard addition using ITP-CZE analysis after SPME pretreatment. The Hcy concentrations in the tested samples of urine and saliva were approximately $22 \mu \mathrm{mol} / \mathrm{L}$ and $6 \mu \mathrm{mol} / \mathrm{L}$ (Fig. 3), respectively.

\section{Conclusion}

The SPME-ITP-CZE method performed on the microchip with conductivity detection and the $\mathrm{CC}$ technique enabled the fast (total analysis time of approximately 20 mins.) and reliable determination of the trace concentrations of Hcy in biological samples such as urine and saliva.

\section{Acknowledgement}

This research was supported by the grants APVV-025912, VEGA 1/0787/18 and UK/312/2017.

\section{REFERENCES}

[1] Selhub, J.: Homocysteine metabolism, Аnnu. Rev. Nutr., 1999 19, 217-246 DOI: 10.1146/annurev.nutr.19.1.217
[2] Kubalczyk, P.; Bald, E.; Furmaniak, P.; Głowacki, R.: Simultaneous determination of total homocysteine and cysteine in human plasma by capillary zone electrophoresis with $\mathrm{pH}$-mediated sample stacking, Anal. Methods, 2014 6(12), 4138-4143 DOI: 10.1039/c4ay00287c

[3] Amores-Sánchez, M.I.; Medina, M.A.: Methods for the determination of plasma total homocysteine: A review, Clin. Chem. Lab. Med., 2000 38(3), 199_ 204 DOI: 10.1515/CCLM.2000.028

[4] Maron, B.A.; Loscalzo, J.: Homocysteine, Clin. Lab. Med., 2006 26(3), 591-609 DOI: 10.1016/j.cll.2006.06.008

[5] Ducros, V.; Demuth, K.; Sauvant, M.P.; Quillard, M.; Caussé, E.; Candito, M.; Read, M.H.; Drai, J.; Garcia, I.; Gerhardt, M.F.: Methods for homocysteine analysis and biological relevance of the results, J. Chromatogr. B Biomed. Anal. Technol. Biomed. Life Sc., 2002 781(1-2), 207-226 DOI: 10.1016/S1570-0232(02)00497-X

[6] Pasas, S.A.; Lacher, N.A.; Davies, M.I.; Lunte, S.M.: Detection of homocysteine by conventional and microchip capillary electrophoresis/electrochemistry, Electrophoresis, 2002 23(5), 759-766 DOI: 10.1002/1522-2683(200203)23:5<759::AID-

[7] Ivanov, A.V.; Luzyanin, B.P.; Moskovtsev, A.A.; Rotkina, A.S.; Kubatiev, A.A.: Determination of total homocysteine in blood plasma by capillary electrophoresis with mass spectrometry detection, J. Anal. Chem., 2011 66(3), 317-321 DOI: 10.1134/S1061934811030075

[8] Melnikov, I.O.; Nazimov, I.V.; Stukacheva, E.A.; Glubokov, Y.: Determination of homocysteine and other low-molecular-weight amino thiols in blood plasma, J. Anal. Chem., 2006 61(11), 1093-1099 DOI: $10.1134 / \mathrm{S} 1061934806110098$

[9] Kubalczyk, P.; Bald, E.: Transient pseudoisotachophoretic stacking in analysis of plasma for homocysteine by capillary zone electrophoresis, Anal. Bioanal. Chem., 2006 384(5), 1181-1185 DOI: 10.1007/s00216-005-0271-7

[10] Bayle, C.; Issac, C.; Salvayre, R.; Couderc, F.; Caussé, E.: Assay of total homocysteine and other thiols by capillary electrophoresis and laser-induced fluorescence detection: II. Pre-analytical and analytical conditions, J. Chromatogr. A., 2002 979(1-2), 255-260 DOI: 10.1016/S0021-9673(02)01504-2

[11] Kang, S.H.; Wei, W.; Yeung, E.S.: On-column derivatization for the analysis of homocysteine and other thiols by capillary electrophoresis with laserinduced fluorescence detection, J. Chromatogr. B Biomed. Sci. Appl., 2000 744(1), 149-156 DOI: 10.1016/S0378-4347(00)00241-3

[12] Caussé, E.; Malatray, P.; Calaf, R.; Charpiot, P.; Candito, M.; Bayle, C.; Valdiguié, P.; Salvayre, R.; Couderc, F.: Plasma total homocysteine and other thiols analyzed by capillary electrophoresis/laser-induced fluorescence de- 
tection: Comparison with two other methods, Electrophoresis, 2000 21(10), 2074-2079 DOI: 10.1002/1522-2683(20000601)21:10<2074::AID-

[13] Caussé, E.; Issac, C.; Malatray, P.; Bayle, C.; Valdiguié, P.; Salvayre, R.; Couderc, F.: Assays for total homocysteine and other thiols by capillary electrophoresis-laser-induced fluorescence detection - I. Preanalytical condition studies, J. Chromatogr. A., 2000 895(1-2), 173-178 DOI: 10.1016/S0021-9673(00)00672-5

[14] Kang, S.H.; Kim, J.W.; Chung, D.S.: Determination of homocysteine and other thiols in human plasma by capillary electrophoresis, J. Pharm. Biomed. Anal., 1997 15(9-10), 1435-1441 DOI: 10.1016/S07317085(96)02051-1

[15] Vecchione, G.; Margaglione, M.; Grandone, E.; Colaizzo, D.; Cappucci, G.; Fermo, I.; D’Angelo, A.; Di Minno, G.: Determining sulfur-containing amino acids by capillary electrophoresis: A fast novel method for total homocyst(e)ine human plasma, Electrophoresis, 1999 20(3), 569-574 DOI: $\quad 10.1002 /(\mathrm{SICI}) 1522-2683(19990301) 20: 3<569::$ AIDELPS569>3.0.CO;2-S

[16] Liang, Q.; Chen, H.; Li, F.; Du, X.: Simultaneous sensitive MEKC-LIF determination of homocysteine, homoarginine, and six arginine metabolic derivatives in fluids from type 2 diabetics with peptic ulcer bleeding, Chromatographia, 2015 78(1516), 1049-1056 DOI: 10.1007/s10337-015-2919-6

[17] Ševčíková, P.; Glatz, Z.; Tomandl, J.: Determina- tion of homocysteine in human plasma by micellar electrokinetic chromatography and in-capillary detection reaction with 2,2'- dipyridyl disulfide, J. Chromatogr. A., 2003 990(1-2), 197-204 DOI: 10.1016/S0021-9673(03)00048-7

[18] Chassaing, C.; Gonin, J.; Wilcox, C.S.; Wainer, I.W.: Determination of reduced and oxidized homocysteine and related thiols in plasma by thiolspecific pre-column derivatization and capillary electrophoresis with laser-induced fluorescence detection, J. Chromatogr. B Biomed. Sci. Appl., 1999 735(2), 219-227 DOI: 10.1016/S0378-4347(99)00425-9

[19] Furmaniak, P.; Kubalczyk, P.; Głowacki, R.: Determination of homocysteine thiolactone in urine by field amplified sample injection and sweeping MEKC method with UV detection, J. Chromatogr. B Anal. Technol. Biomed. Life Sci., 2014 961, 36-41 DOI: 10.1016/j.jchromb.2014.04.051

[20] Chand, R.; Han, D.; Islam, K.; Yeon, I.J.; Ko, S.S.; Kim, Y.S.: Microchip capillary electrophoresis based separation and detection of cysteine and homocysteine, Adv. Mat. Res., 2013 647, 482-486 DOI: 10.4028/www.scientific.net/AMR.647.482

[21] Kaniansky, D.; Masár, M.; Bodor, R.; Žúborová, M.; Ölvecká, M.; Jöhnck, M.; Stanislawski, B.: Electrophoretic separations on chips with hydrodynamically closed separation systems, Electrophoresis, 2003 24(12-13), 2208-2227 DOI: 10.1002/elps.200305474 